\title{
Adaptive Method of Comparison to Identify for Force Ripples in Wavelet Coefficients of Two Types Linear Motors with Permanent Magnets
}

\author{
Edwin Laniado-Jacome ${ }^{1^{*}}$, Jaime Montoya-Larrahondo ${ }^{3}$, \\ Gabriel González-Palomino ${ }^{1}$ and Yimy E. Garcia-Vera ${ }^{2}$ \\ ${ }^{1}$ Autonomous University of the West-Cali, Colombia. \\ ${ }^{2}$ University of Cundinamarca, Colombia. \\ ${ }^{3}$ University Carlos III of Madrid, Spain.
}

Authors' contributions

This work was carried out in collaboration between all authors. All authors read and approved the final manuscript.

\section{ABSTRACT}

This article proposes a numerical model of Permanent Magnet Linear Synchronous Motors (PMLSMs) for use as a tracking mechanism for the transport system. This paper studies the behavior under operating two types of linear motors to analyze and compare the system of forces and vibration levels to determine its efficiency as a transport system. The first model of motor has configuration of opposite poles and second has Halbach type configuration, are analyzed by the finite element method with commercial software FLUX'TM. The data of variation of force called ripple are analyzed with techniques for vibration signals using wavelet coefficients for classification of MatLab ${ }^{\mathrm{TM}}$ software to determine the concentration of vibrational energy levels and the parameters identified for each proposed linear motor.

Keywords: Halbach; opposite poles; linear motor; wavelet coefficients. 


\section{INTRODUCTION}

The synchronous linear motors are used by industry to improve production rates and have more accuracy in manufacturing $[1,2,3]$. This work shows a drive system driven by the effects of thrust and attraction of a set of magnets to the stator, this drive system is a synchronous linear motor with permanent magnets (PMLSM). We analyze the behavior of motor movements taking time signals magnitudes as the driving force. The time signal is obtained due to the undulations of the forces emitted by this linear motor will be used to understand the vibrational energy levels that govern the operation of such motor. This paper proposes an optimized method of identification of linear motor operation and detection of failure in the possible variation of the coefficients.

This research proposes two numerical models of linear motor with different types of settings to calculate the magnitudes of strength, concentration levels of vibrational energy and identification of parameters of each motor. The first model of motor has configuration of opposite poles; for this first model uses different angular inclinations (Skew) of the magnets to determine the relationship between magnitudes of force vs. ripple [4,5]; second has Halbach type configuration, This setting directs the flow every $90^{\circ}$, closing the magnetic field in three magnets [6,7]. PMLSMs these two types of work as a drive mechanism to adjust in a transport system, suitable for people and cargo. It examines the thrust and attraction forces to know the maximum magnitudes per unit area resulting from these linear motors. A common phenomenon in the movement of these motors is the ripple. The ripple is generated by the variation of magnetic forces to be attracted by the stator; this phenomenon is the same as presented by the rotating machines in operation called vibrations $[8,9,10]$. The signals from the vibrations are analyzed by the wavelet technical of classification coefficients to identify the natural frequencies of operation of each engine and vibrational energy levels that contribute to the support structure of the system [11,12].

Fig. 1 shows PMLSMs, part A of the figure (left) shows the linear motor magnets opposite poles available, with stator slot open and winding concentrated or short pitch and part B (right) shows the linear motor model Halbach array, this is the stator slot open with windings distributed or pole pitch.
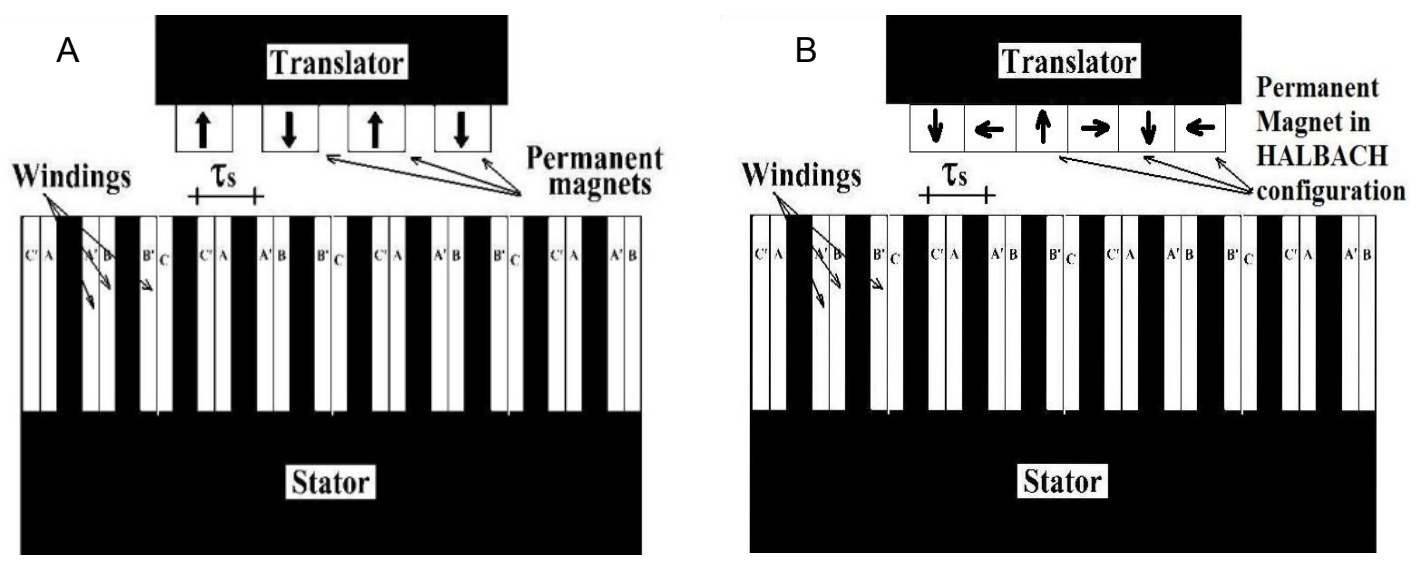

Fig. 1. Synchronous Linear Motors Permanent Magnet 
Some studies of linear motors vibration frequencies calculated under the Fast Fourier Transform (FFT) technique, but this technique does not qualify, nor characterizes the types of engine that composes a system [13,14] other studies using the technique of wavelet coefficients only rotary system [15].

The line motor which is defined in this article as a drive system is analyzed to determine the magnitude of magnetic force and the vibration levels of energy due to the undulations of the results of the magnetic forces to the stator to be considered system transportation.

\section{MAGNETIC FIELDS ANALYSIS}

Magnetic field analysis of PMLSMs made the study of two types of flow lines of force of great importance to this research, the first is the lines of magnetic force applied to the stator to generate movement and the second magnetic flux that is transmitted within the set of coupled magnets the translator.

The magnetic field analysis determines the magnitude of force with ability to move a load structure but highly dependent on the direction of flow. For the model proposed in this paper of the type of opposite poles, the magnets are located at a separation distance of $100 \mathrm{~mm}$, which is why the magnetic field generation for this model can be less intense than the type Halbach. Halbach's model requires three magnets together to the stator can be closed and the flow field is transmitted with the variable pitch stator during operation of the motor.

The analysis of magnetic flux generates magnetic force results in Newton during operation of the linear motor but these forces vary with time, is called ripple in this paper will serve to identify the waves and frequencies of each proposed linear motor.

The permanent magnets synchronous machines are traditionally made of ferrite, its low cost and because they have an excellent property of linear demagnetization, its limitations is its low residual magnetism. The latest materials to manufacture permanent magnets are rare earth samarium-cobalt as $\left(\mathrm{SmCo}_{5}\right.$ or $\left.\mathrm{Sm}_{2} \mathrm{Col}_{7}\right)$, these presents the best characteristics of magnetic properties, but its production depends on special applications where small size and weight to justify their high cost. The other one is the Neodymium-Iron-Boron (Nd-Fe-B), these has high remanence and high linearity of demagnetization but is affected by temperature. We selected the rare earth material Neodymium-Iron-Boron ( $\mathrm{Nd}-\mathrm{Fe}-\mathrm{B}$ ) for permanent Magnets, to present the characteristic of having remanence and high linearity of demagnetization.

The characteristics of the permanent magnets, is obtained from the values of the $\mathrm{B}-\mathrm{H}$ curve with the following equations:

$$
B=\mu H
$$

Where $\mu$ is the permeability of the ferromagnetic material and is the same material for the stator core, $B_{r}$ Flux Density Remanence. Under these conditions we find that the residual flux density $B_{r}$ is $1.15(\mathrm{~T})$ and relative permeability $\mu=1.05$. Stator uses a feature of nonlinear magnetic saturation in the stator iron core with initial relative permeability of 2500 and saturation magnetization $1.9(\mathrm{~T})$.

$$
\mu=\mu_{0} \mu_{\text {iron }}
$$


Numerical models were analyzed with magnetic force results calculated by Maxwell Stress Tensor Method [16,17] in the theory of electromagnetism for stationary fields [18], when translator is in synchronism with current field produced by the winding. Each model has about 30000 nodes in the mesh without physical contact nodes, although the models have included electromagnetic contact nodes [19]. The solutions of the variables of the models were made on three axes.

Table 1 shows the properties and boundary conditions of the model to simulate the operation of a linear motor at a close distance of $40 \mathrm{~mm}$, with these conditions may analyze the levels of vibration generated by other types proposed in this research.

Table 1. Features and conditions of the model

\begin{tabular}{lll}
\hline Description & PMLSM & HALBACH \\
\hline Relative permeability of iron & 2500.00 & 2500.00 \\
Relative permeability of the permanent magnet & 1.05 & 1.05 \\
Current density $\left(\mathrm{A} / \mathrm{mm}^{2}\right)$ & 8.33 & 8.33 \\
Speed of translator $(\mathrm{m} / \mathrm{s})$ & 4.05 & 4.05 \\
Elements by nodes & 4000.00 & 6000.00 \\
Nodes & 15000.00 & 32000.00 \\
\hline
\end{tabular}

The magnetic field study analyzes the behavior of the magnitudes of the magnetic forces that under these conditions it takes next results. The other item is placed magnets, and is called the field excitation system. Translator has a mesh with orientation load magnetic of Halbach type for second model.

Fig. 2 shows a mesh translator with optimal density to calculate the variation of force. The translator would guide the magnetic flux to generate the force necessary to operate with the stator to move any type of load. The magnetic flux in the Halbach configuration has a greater distance moved, came to the stator flow at an angle that would generate larger thrust force of attraction. In the configuration of magnets in the Halbach type translator are two flow circuitry of magnetic force, these circuits vary little due to the dynamic movement of the excitation on the stator pole pitch.

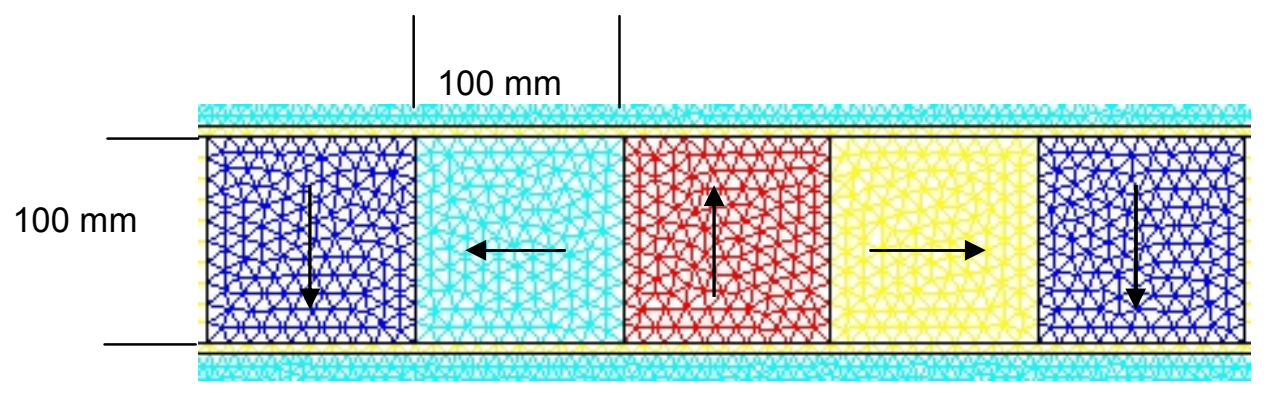

Fig. 2. Translator mesh with Permanent Magnet of Halbach configuration

The flow of the magnetic force of the linear motor type Halbach shows in Fig. 3 as the first magnet $(A)$ directs movement with the effect of the thrust force to the right, opening the flow passage within the first circuit of three magnets (blue). The magnet $(C)$ is in the middle of the translator magnet assembly, the magnet closes the flow for the two circuits of the magnetic 
field of translator and its goal is to generate the repulsive force, led the translator in the direction of movement.

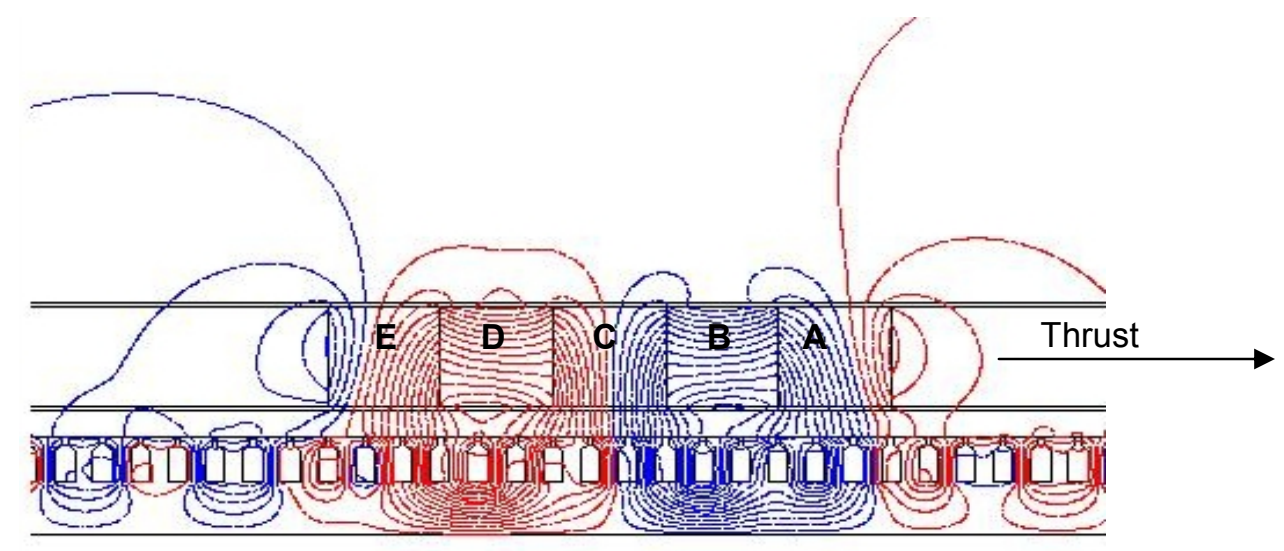

Fig. 3. Lines of magnetic forces working with the excitation of the stator

In the translator of this motor are two flow circuits of magnetic force, the volume of this flow remains nearly constant no greater dispersion of the lines of force because the magnets (poles) are joined by other magnets $(B, D)$ perpendicular to them.

PMLSMs magnets with opposite poles orientation shown in Fig. 4 has a similar mesh-type Halbach, the main feature that distinguishes this motor is the orientation of the flow by analyzing the separation of the magnets and how close the magnetic circuit that generates greater dispersion of the force lines in the top of the translator due to separation of the magnets, with this thrust force is lost due to the decreased volume of flow into the stator.

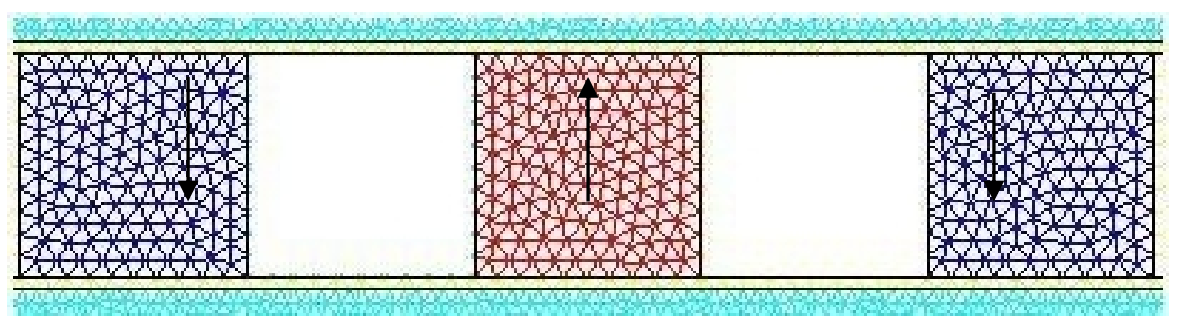

Fig. 4. Translator mesh with Permanent Magnet of opposite poles configuration.

Fig. 5 shows three-phase winding of stator has the negative phase sequence $A^{\prime}-\mathrm{C}-\mathrm{B}^{\prime}$. The distribution of the winding coils is shown below:

Fig. 6 shows a stator contains three-phase winding of the coils, four poles in 24 slots semiclosed of the iron core, with the pole pitch of $\mathrm{T} 199.8 \mathrm{~mm}$, stator height $100 \mathrm{~mm}$. The proposed drive system consists of 5 permanent magnets and a fixed stator current in three phases, this system has been tested with two different configurations of magnetic flux in the set of magnets that are compared. 


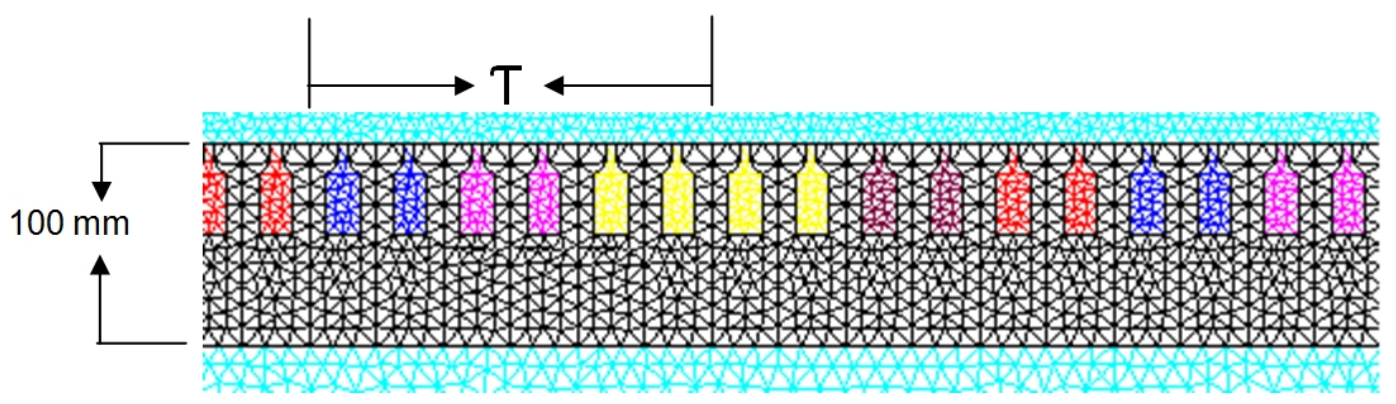

Fig. 5. Stator mesh with three phases.

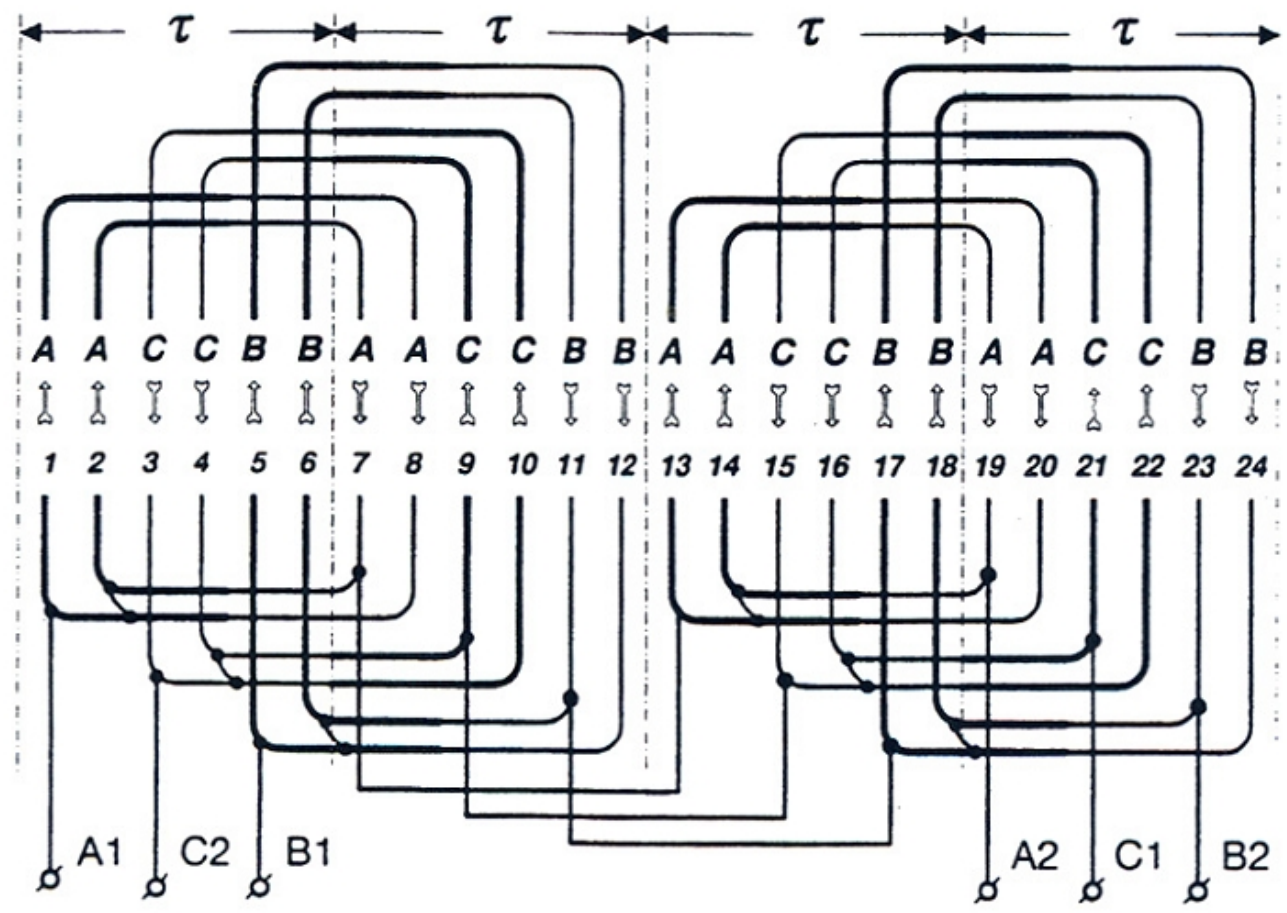

Fig. 6. Stator with three-phase

The connection system of permanent magnets Halbach configuration forms a strong magnetic flux within the set of magnets in the translator fed by the immediate junction of the magnets with an angle of lesser magnitude.

Fig. 7 shows the distribution of magnetic flux density in permanent magnets and is described as the flow may take more willing to be bonded magnets and at the junction of the magnets no more than 90 degrees apart. 

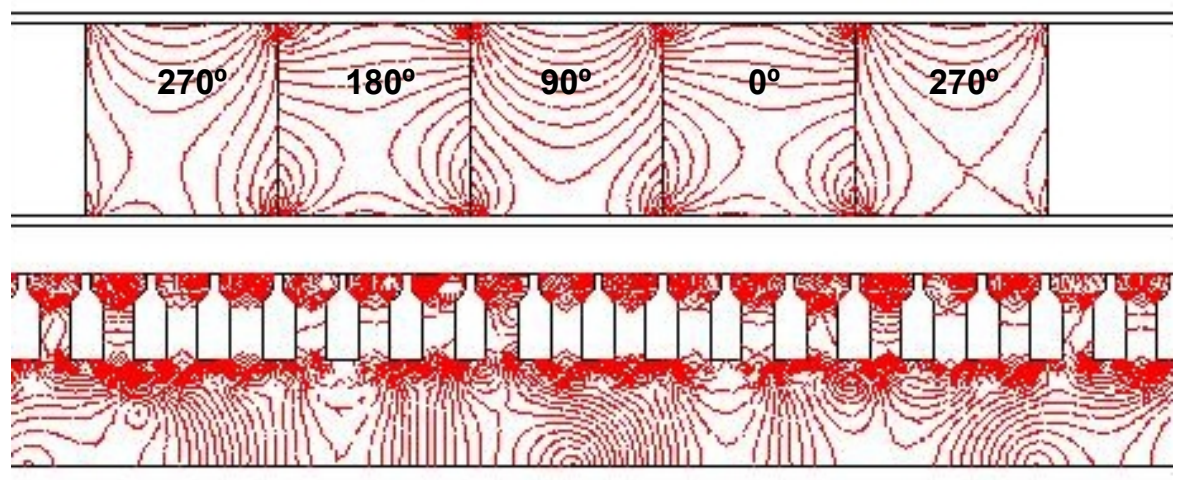

Fig. 7. Density distribution of magnetic flux in the stator and the Translator

The magnetic flux is highest magnitude (see A in Fig. 8) that the magnetic force (see B) generated in the magnet that drives the thrust, the magnetic flux according to Maxwell's equations show the full flow resultant force on the set of magnets.

While Fig. 8 shows values of strength and high flow magnitudes, able to move load, the ripples generated by the variation of the force due to the impulses of the stator is analyzed in this research because of its effects on the structure and the load, and the magnetic flux by the high stiffness material of magnets.
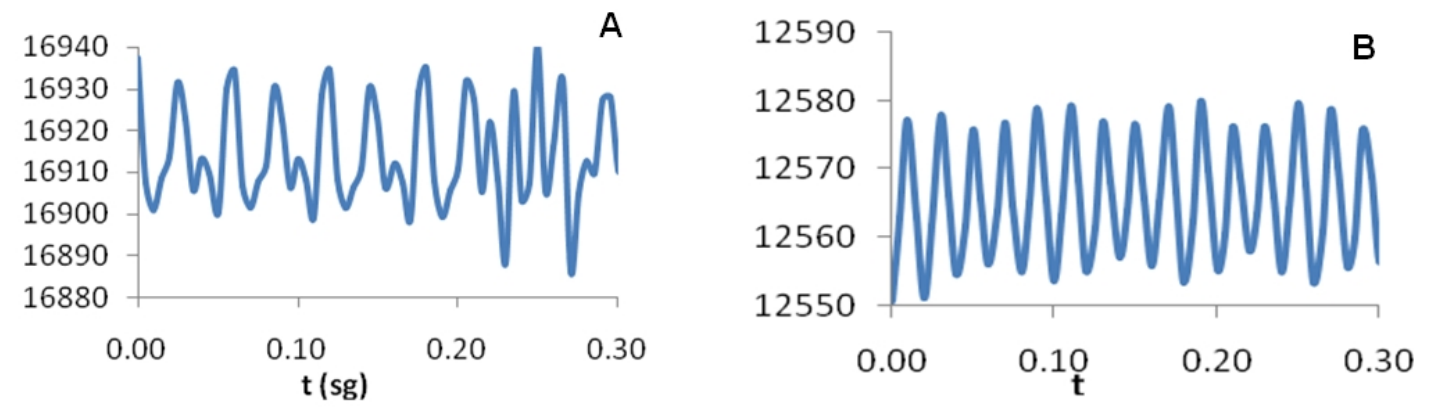

Fig. 8. Results of the Flow and magnetic force of the magnet assembly of the translator at Halbach configuration.

\section{ANALYSIS OF TRACTION SYSTEM}

This research studies a new traction system consists of the attraction and thrust of a set of permanent magnets to the drive of a fixed stator is proposed for this work two types different configurations to find the magnitudes that exist in the operation forces and vibrational energy levels generated by the ripple.

Any drive system consists of a rotating motor, a structure that supports them and a rolling system $[20,21,22]$. The PMLSMs have two principal components or parts, the stator and the slider (translator), one of the pieces are located in the excitation windings are fed with a three-phase AC voltage that produces a moving magnetic field, this element is called the armature. 
There are two numerical models proposed for the analysis in this research, numerical models are presented at 2D with 3 DOF under analysis by the method of finite element with commercial code FLUX ${ }^{\mathrm{TM}}$, the acquired data for comparison between the two models are with electromagnetic forces between the magnets permanent and the stator during time of operation.

The PMLSMs, the speed of the translator is defined using the equations of motion of translator and the pole pitch with the frequency three-phase of the armature winding. The analysis is done at $50 \mathrm{~Hz}$.

$$
v=v_{s}=2 f \tau=\frac{\omega}{\pi} \tau
$$

Table 2 shows the dimensions of the two types of models proposed. These two types of PMLSMs have been simulated with physical boundary conditions mechanical and magnetic properties similar to a thrust as speed depends on the frequency of translation.

Table 2. Dimensions model

\begin{tabular}{lll}
\hline Description & Opposite Poles & HALBACH \\
\hline Stator: & 3240 & 3240 \\
Length & 100 & 100 \\
Depth & 15 & 15 \\
Yoke's Height & 15 & 7.5 \\
Slots Width & 27 & 13.5 \\
Slot Step & & \\
Translator: & 162 & 500 \\
Length & 100 & 100 \\
Depth & 5 & 100 \\
Height of Magnets & 27 & 100 \\
Width of Magnets & 40.5 & 40.5 \\
Polar Step & 1 & 50 \\
Air-Gap & & \\
\hline
\end{tabular}

All dimensions are in $\mathrm{mm}$

The displacement of translator is a distance equal to one pole pitch of $40.5 \mathrm{~mm}$ to define simulation time. Then, the duration of movement will be:

The currents of the armature winding varies sinusoidally during the period of time, choose the following expression:

$$
I(t)=I_{\max } \cos (\omega t+\varphi)[A]
$$

Where

$I_{\max }$ : Maximum current value reaches a phase of the armor,

$\omega$ : Angular frequency of the current,

$t$ : Runtime of the simulation,

$\varphi$ : Angle of the corresponding phase current.

Being a balanced three-phase circuit the value of $(\varphi)$ in each phase is: 


$$
\varphi_{A}=0^{\circ} ; \varphi_{B}=-120^{\circ} ; \varphi_{C}=120^{\circ}
$$

This analysis is performed to determine if the magnitudes of the forces have the ability to move a structure with load of persons or merchandise and the level of vibrational energies presented in this drive system. The vibration energy groups the amplitudes of oscillation of a signal, which under a frequency analysis cannot be determined, which is why this research proposes to compare the coefficients of vibrational energy of two types of linear motors analyzed by the wavelet. This analysis will determine which of the two PMLSMs provide more power of vibration to the structure that supports it.

For this Traction system is important to know and have control of the force magnitudes in the set of magnets and their ability to thrust exerted by the activation of the stator to tilt under load.

Fig. 9 shows two types of linear motors with similar features and conditions (Halbach (A), oppossitte poles $(B) ; T_{\mathrm{s}}=1$ ), this force can drive load. $\boldsymbol{T}_{\mathrm{s}}$ is the angle of inclination of the magnets with respect to the surface of the flow towards the stator. Undulation levels lower considerably with a Halbach motor. The results of the two models show evidence of magnetic force with the ability to move cargo, but the magnitude of these results can be controlled, changing the current density, the more amperage greater force in the linear motor.
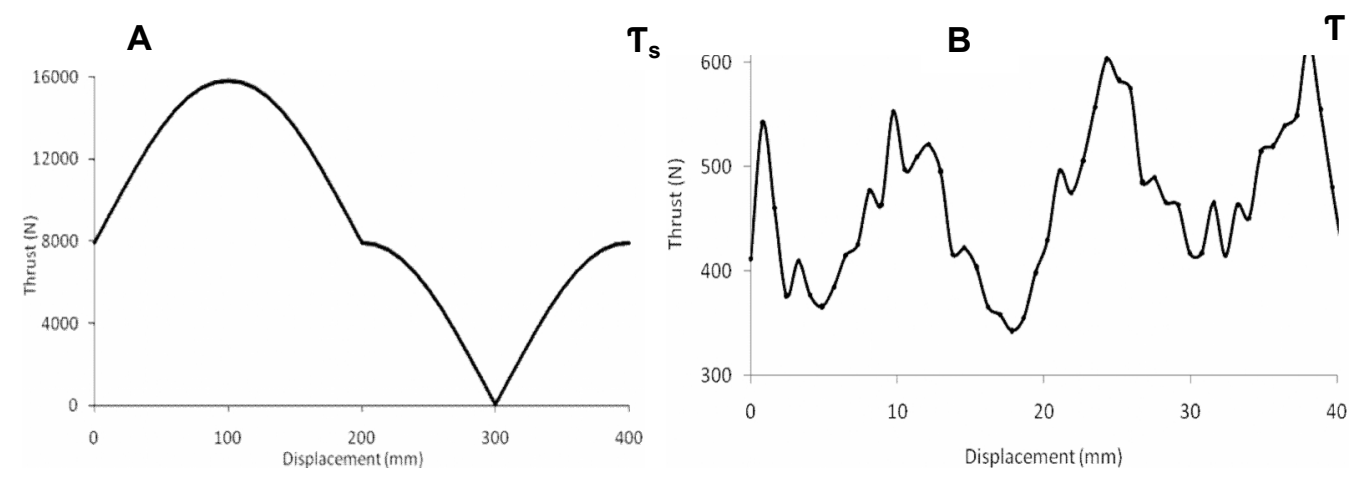

Fig. 9. Magnetic force of the magnetic set at translator

\subsection{Analysis of Identification by Coefficients}

Wavelet coefficient analysis is to identify the signal an optimized way for each of the linear motors into operation, this method identifies the linear motor in operation or if it is identified one can detect incipient damage. The type of analysis chosen wavelet coefficients at low frequencies is of type Daubechies.

Common waves are divided into operating frequency range, the analysis is performed to detect the levels of deviation of each linear motor and the damage that can occur immediately, as well as a component to identify the linear motor is operating in a complex system. 
Table 3 shows that in a frequency range single engine is identified by a single value within that range, optimizing any type of procedure. The coefficients are shown frequency range is family Daubechies wavelet (db4 and DB6) were used for this detection [23]

Table 3. Wavelet coefficients for 2 Linear Motor type

\begin{tabular}{llll}
\hline Frequency range & Detail & Poles & Halbach \\
\hline $1250-2500$ & d1 & 16.747 & 17.101 \\
$625-1250$ & d2 & 18.926 & 14.131 \\
$312.5-625$ & d3 & 26.370 & 29.629 \\
$156.25-312.5$ & d4 & 54.094 & 24.582 \\
$78.125-156.25$ & d5 & 19.399 & 26.281 \\
$39.0625-78.125$ & d6 & 3.780 & 5.650 \\
\hline
\end{tabular}

\section{CONCLUSION}

The proposed numerical model of a linear motor with permanent magnet of the Halbach configuration and opposite poles is presented as the only option for this type of analysis and optimized to identify the wavelet coefficients for each model presented.

The wavelet coefficients are a way to determine the type of linear motor in operation. These coefficients can have intervals where it is shown that to overcome some of its limitations identify incipient fault

In this research, the vibration levels of two types of linear motors is shown to operate in the future as a traction motor for human transport or freight

Halbach type linear motor show lower levels of vibration, this is due to the orientation of the magnetic field lines of magnets arranged in this configuration.

\section{COMPETING INTERESTS}

Authors have declared that no competing interests exist.

\section{REFERENCES}

1. Jaewon $\mathrm{L}$, Jung $\mathrm{KH}$. Cogging force reduction in permanent magnet linear motor using phase set shift. Presented at Electrical Machines, ICEM 2008.18th International Conference on; 2008.

2. Suzuki K, Kim JY, Dohmeki H. Proposal of the section change method of the stator block of the discontinuous stator permanent magnet type linear synchronous motor aimed at long-distance transportation. Presented at Electrical Machines, ICEM 2008.18th International Conference on; 2008.

3. Yoshimura T, Kim JH, Watada M, Torii S, Ebihara D. Analysis of the reduction of detent force in a permanent magnet linear synchronous motor. Magnetics, IEEE Transactions. 1995;31(6):3728-3730. DOI: 10.1109/20.489752.

4. Lee YD, Hwang $\mathrm{Cl}$, Kang HG, Kim TG. 3D finite element analysis of skew and overhang effects in permanent magnet linear synchronous motor. Presented at 2006 12th Biennial IEEE Conference on Electromagnetic Field Computation; 2006. 
5. Wang FC, Shen XJ, Wang LY, Wang L, Jin JM. A new method for reduction of detent force in permanent magnet flux-switching linear motors. Magnetics, IEEE Transactions. 2009;45(6):2843-2846.

6. Xiaoyuan $\mathrm{W}$, Wang $\mathrm{Y}$, Wang $\mathrm{Q}$. Effects of different permanent magnet structures on the air gap magnetic field of linear motors. Presented at Automation Congress, WAC, World; 2008.

7. Zhao S, Tan KK. Adaptive feedforward compensation of force ripples in linear motors. Control Eng Pract. 2005;13(9):1081-1092.

DOI: http://dx.doi.org/10.1016/j.conengprac.2004.11.004.

8. Braun S, Ewins D, Rao SS. Encyclopedia of vibration, volume 2, chapter computational methods: Object oriented programming in FE analysis by klapka I, cardona A, devloo P; 2001.

9. Youn WS, Lee JJ, Yoon SH, Koh SC. A new cogging-free permanent-magnet linear motor. Magnetics, IEEE Transactions. 2008;44(7):1785-1790.

10. Yousefi $\mathrm{H}$, Hirvonen $\mathrm{M}$, Handroos $\mathrm{H}$, Soleymani A. Application of neural network in suppressing mechanical vibration of a permanent magnet linear motor. Control Eng. Pract. 2008;16(7):787-797. DOI: http://dx.doi.org/10.1016/j.conengprac.2007.08.003.

11. Burrus SC, Gopinath AR, Guo H, Odegard EJ, Selesnick WI. Introduction to Wavelets and Wavelet Transforms: A Primer 1998;23.

12. Rubini R, Meneghetti U. Application of the envelope and wavelet transform analyses for the diagnosis of incipient faults in ball bearings. Mechanical Systems and Signal Processing. 2001;15(2):287-302. DOI: http://dx.doi.org/10.1006/mssp.2000.1330.

13. Boyes DJ. Reciprocating Machinery Analysis with an FFT Analyser; 1975.

14. Cizek V. Methods of Computation of Discrete Fourier Transforms In: Anonymous Disctrete Fourier Transforms and their Applications. 1985;98-120.

15. Fu S, Muralikrishnan B, Raja J. Engineering surface analysis with different wavelet bases. Journal of Manufacturing Science and Engineering. 2003;125(4):844-852.

16. Zienkiewicz CO. Finite Element Method. 1967 Published Under Title: Finite Element Method in Structural and Continuum Mechanics; 1971 Published Under Title: Finite Element Method in Engineering Science; 1977.

17. Zienkiewicz $\mathrm{CO}$, Cheung KY. The finite element method in structural and continuum mechanics: Numerical Solution of Problems in Structural and Continuum Mechanics; 1967.

18. Jin MJ. The finite element method in electromagnetics. John Wiley \& Sons, New York; 1993.

19. Volakis LJ, Chatterjee A, Kempel CL. Finite element methods for electromagnetics: Antennas, microwave circuits and scattering applications. A John Wiley \& Sons, Inc., Publication, New York; 1998.

20. Lieh J. Closed-form solutions for vehicle traction problems. Proc. Inst. Mech. Eng. Pt. D. J Automobile Eng. 2002;216(12):957-963.

21. Radosavljevic A. Measurement of train traction characteristics. Proc. Inst. Mech. Eng. Pt. F. J Rail Rapid Transit. 2006;220(3):283-291.

22. Seo IS, Park SC, Choi HS, Han JY, Kim HK. Reliability management and assessment for the electric traction system on the korea high-speed train. Proc. Inst. Mech. Eng. Pt. F. J Rail Rapid Transit. 2010;224(3):179-188. 
23. Saraswathy J, Hariharan M, Vikneswaran Vijean, Sazali Yaacob, Wan Khairunizam. Performance Comparison of Daubechies Wavelet Family in Infant Cry Classification. 8th International Colloquium on Signal Processing and its Applications; 2012.

(C) 2014 Laniado-Jacome et al.; This is an Open Access article distributed under the terms of the Creative Commons Attribution License (http://creativecommons.org/licenses/by/3.0), which permits unrestricted use, distribution, and reproduction in any medium, provided the original work is properly cited.

Peer-review history:

The peer review history for this paper can be accessed here: http://www.sciencedomain.org/review-history. php?iid=492\&id=5\&aid=4273 